\title{
Adherence to GLP-I receptor agonist therapy administered by once-daily or once-weekly injection in patients with type 2 diabetes in Germany
}

This article was published in the following Dove Press journal:

Diabetes, Metabolic Syndrome and Obesity:Targets and Therapy 28 June 2016

Number of times this article has been viewed

\author{
Qing Qiao' \\ Mario JNM Ouwens' \\ Susan Grandy ${ }^{2}$ \\ Kristina Johnsson' \\ Karel Kostev ${ }^{3}$ \\ 'Global Medicines Development, \\ AstraZeneca, Gothenburg, Sweden; \\ ${ }^{2}$ Global Medicines Development, \\ AstraZeneca, Gaithersburg, MD, \\ USA; ${ }^{3}$ Epidemiology and Evidence- \\ Based Medicine, Real-World Evidence \\ Solutions, IMS Health, Frankfurt am \\ Main, Germany
}

Aim: This study aimed to compare 6-month adherence to therapy with exenatide once weekly $\left(\right.$ Bydureon $^{\circledR}$ ) vs liraglutide once daily $\left(\right.$ Victoza $\left.^{\circledR}\right)$ in patients with type 2 diabetes under primary care in Germany.

Methods: A nationwide longitudinal prescription database (LRx), (between January 2011 and September 2014) was used to analyze adherence to therapy. The proportion of days covered (PDC) by prescription was used as a measure of adherence in the 6-month postindex period. Logistic regression analyses were performed to investigate the associations between glucagonlike peptide-1 receptor agonist therapy adjusting for age, sex, and cotherapy.

Results: Therapy was initiated in 5,449 patients with exenatide once weekly (age: $59.7 \pm 11.8$ years; $51.4 \%$ were male) and in 24,648 patients with liraglutide once daily (age: $59.4 \pm 11.4$ years; $49.7 \%$ were male). The median PDC was 0.88 for exenatide once weekly and 0.77 for liraglutide once daily $(P<0.05)$. Once-weekly exenatide was associated with significantly higher adherence. Odds ratio ( $95 \%$ confidence interval) for having a PDC of $\geq 0.80$ was 1.78 (1.62-1.96) for exenatide once weekly compared with liraglutide once daily after adjusting for age, sex, and cotherapy.

Conclusion: Adherence to treatment with exenatide once weekly was significantly increased compared to that with liraglutide once daily over 6 months in patients with type 2 diabetes.

Keywords: type 2 diabetes, GLP-1 receptor agonists, adherence

\section{Introduction}

Glucagon-like peptide-1 (GLP-1) is an incretin hormone secreted from gastrointestinal cells shortly after an ingested meal. ${ }^{1,2}$ GLP-1 stimulates insulin secretion in a glucosedependent manner, suppresses glucagon secretion, delays gastric emptying, and suppresses appetite. ${ }^{1,2}$ Because of the decreased release and response of incretins in patients with type 2 diabetes, the incretin axis is a target for pharmacologic therapy. ${ }^{1,2}$ The clinical advantages of GLP-1 receptor agonists (GLP-1 RAs) are significant improvements in glycemic control, with relevant weight loss, and a low risk of hypoglycemia. ${ }^{3}$ In patients with type 2 diabetes, glucose control is highly dependent on adherence to medication regimens, and nonadherence has been associated with increased all-cause mortality and all-cause hospitalization. ${ }^{4}$ The complexity of a dosing regimen is associated with nonadherence. We hypothesized that once-weekly injections of GLP-1 RA may improve patients' adherence compared with once-daily GLP-1RA therapy. The aim of our study was to compare 6-month adherence to therapy with exenatide once weekly vs liraglutide once daily in patients with type 2 diabetes initiating treatment in primary care in Germany.
Correspondence: Karel Kostev Epidemiology, Real-World Evidence Solutions, IMS Health $\mathrm{GmbH}$ and $\mathrm{Co}$, OHG, Darmstädter, Landstraße I08, Frankfurt am Main 60598, Germany Tel +49696604 4878

Email kkostev@de.imshealth.com 


\section{Methods}

The longitudinal prescriptions database (LRx) (IMS Health, Frankfurt am Main, Germany) collects pharmacy data from data centers where the prescriptions of all German patients with statutory health insurance are processed for reimbursement purposes. ${ }^{5}$ Data entries covered patient-specific data over time, including the patient's anonymized identification number, age, sex, insurance company, and place of living, as well as prescription information including the prescriber's anonymized identification number, prescription date, and package information. Information on diagnoses is not part of these data sets. The LRx database currently contains $\sim 60 \%$ of all prescriptions reimbursed nationwide in Germany. ${ }^{5}$ Considering that exenatide once weekly was launched in Germany in September 2011 (2 years after once-daily liraglutide was available in the German market), the study period for this study was set from January 2011 to September 2014, including a 9-month follow-up period. Patients who initiated GLP-1 RA therapy between January 1, 2011 and December 31, 2013 (index date) and who had at least 6 months' follow-up data after the index date were included. Baseline demographic characteristics 6 months before the index date were collected from patients' records. In Germany, no ethics votum is needed for studies based on anonym epidemiological data. The IRB from IMS Health deemed ethical approval and written patient consent were not required as no ethics votum is needed for studies based on anonym epidemiological data.

Therapy adherence to exenatide once weekly and liraglutide once daily was measured using the proportion of days covered (PDC) with the index GLP-1RA in the 6-month postindex period. PDC was calculated by taking the total number of days supplied per patient during the postindex 6-month period and dividing that by 180 days. The number of days supplied was calculated as follows: number of entities within a pack $\times$ number of packs within the interval $\times 7$ for exenatide once weekly; and number of milligrams $\times$ number of entities within a pack $\times$ number of packs within the interval/1.3 (median dose) for liraglutide once daily. Good adherence was defined as a PDC $\geq 0.80$.

Descriptive statistics were given and differences in characteristics (patients with GLP-1RA therapy once weekly vs once daily) were assessed using $t$-tests or chi-square tests. A multivariable logistic regression model was fitted with PDC $\geq 0.80$ (vs $<0.80)$ as the dependent variable and therapy with exenatide once weekly vs liraglutide once daily, age, sex, and glucose-lowering cotherapy as covariables. $P$-values $<0.05$ were considered statistically significant. All analyses were carried out following the German good practice recommendations of secondary data analysis using SAS 9.3 (SAS Institute, Cary, NC, USA). ${ }^{6}$

\section{Results}

Between January 2011 and September 2014, 5,449 patients initiated therapy with exenatide once weekly and 24,648 patients with liraglutide once daily. The baseline characteristics and glucose-lowering comedications are listed in Table 1. There were no significant differences in age and sex distributions between the two GLP-1RA groups, except for a slightly higher proportion of patients in the age group of $>70$ years in the exenatide once-weekly group. Metformin and dipeptidyl peptidase 4 (DPP-4) inhibitors (DPP-4is) were more often prescribed in patients on exenatide once weekly than in liraglutide once daily treatment, whereas insulin was more often found among liraglutide users (all $P<0.001$ ) (Table 1).

The median PDC was significantly higher for exenatide once weekly (0.88) than for liraglutide once daily (0.77), particularly higher among patients between 51 years and 70 years of age ( $0.92 \mathrm{vs} 0.79)$ (Table 2$)$. The proportion with good adherence ( $\mathrm{PDC} \geq 0.80$ ) was also significantly higher among patients on exenatide once weekly than those on liraglutide once daily therapy ( $53.4 \%$ vs $48.1 \% ; P<0.001)$. This difference was consistent across sex and different age groups (Table 2). Cumulative distribution of the PDC is shown in Figure 1. A large percentage of patients fully adhered to treatment.

Table I Baseline characteristics of type 2 diabetes patients initiating therapy with exenatide once weekly or liraglutide once daily

\begin{tabular}{|c|c|c|c|}
\hline Variable & $\begin{array}{l}\text { Exenatide } \\
\text { once } \\
\text { weekly } \\
(n=5,449)\end{array}$ & $\begin{array}{l}\text { Liraglutide } \\
\text { once } \\
\text { daily } \\
(n=24,648)\end{array}$ & $P$-value \\
\hline Male (\%) & 51.4 & 49.7 & 0.340 \\
\hline Age, years (mean $\pm S D)$ & $59.7 \pm 11.8$ & $59.4 \pm I I .4$ & 0.098 \\
\hline \multicolumn{4}{|l|}{ Age groups (\%) } \\
\hline$\leq 50$ years & 21.2 & 21.6 & 0.632 \\
\hline $5 I-60$ years & 30.2 & 31.5 & 0.167 \\
\hline $61-70$ years & 29.1 & 29.1 & 0.965 \\
\hline$>70$ years & 19.6 & 17.8 & 0.026 \\
\hline \multicolumn{4}{|l|}{ Cotherapy with (\%) } \\
\hline Metformin only & 35.5 & 33.2 & $<0.001$ \\
\hline Metformin + sulfonylurea & 11.9 & 10.3 & $<0.001$ \\
\hline Metformin + DPP-4 inhibitors & 9.9 & 6.8 & $<0.001$ \\
\hline Metformin + insulin & 11.8 & 23.1 & $<0.001$ \\
\hline Insulin & 3.9 & 6.4 & $<0.001$ \\
\hline DPP-4 inhibitors & 5.4 & 2.8 & $<0.001$ \\
\hline GLP-IRA monotherapy & 13.7 & 10.9 & $<0.001$ \\
\hline Other combinations & 7.9 & 6.5 & 0.088 \\
\hline
\end{tabular}

Note: LRx database, January 20I I-September 20I4, Germany.

Abbreviations: DPP-4, dipeptidyl peptidase 4; GLP-IRA, glucagon-like peptide-I receptor agonist; LRx, longitudinal prescriptions database. 
Table 2 PDC in the first 6 months in patients with type 2 diabetes initiating therapy with either exenatide once weekly ( $n=5,449)$ or liraglutide once daily $(n=24,648)$

\begin{tabular}{lllll}
\hline & Median PDC & PDC $\geq \mathbf{0 . 8 0}(\%)$ & \\
\cline { 2 - 5 } & Exenatide once weekly & Liraglutide once daily & Exenatide once weekly & Liraglutide once daily \\
\hline Total $^{\mathrm{a}}$ & $0.88^{*}(0.47-1.00)^{\mathrm{b}}$ & $0.77^{*}(0.46-1.00)^{\mathrm{b}}$ & $53.4^{*}$ & $48 . I^{*}$ \\
Male & $0.85^{*}(0.47-1.00)^{\mathrm{b}}$ & $0.77^{*}(0.49-1.00)^{\mathrm{b}}$ & $52.4^{*}$ & $48.7^{*}$ \\
Female & $0.86^{*}(0.47-1.00)^{\mathrm{b}}$ & $0.77^{*}(0.46-1.00)^{\mathrm{b}}$ & $52.0^{*}$ & $47.5^{*}$ \\
Age groups & & & & \\
$\leq 50$ years & $0.78^{*}(0.47-1.00)^{\mathrm{b}}$ & $0.77^{*}(0.45-1.00)^{\mathrm{b}}$ & $49.6^{*}$ & $45 . I^{*}$ \\
$51-60$ years & $0.92^{*}(0.47-1.00)^{\mathrm{b}}$ & $0.79^{*}(0.53-1.00)^{\mathrm{b}}$ & $55.3^{*}$ & $49.4^{*}$ \\
$61-70$ years & $0.92^{*}(0.47-1.00)^{\mathrm{b}}$ & $0.79^{*}(0.46-1.00)^{\mathrm{b}}$ & $56.3^{*}$ & $49.3^{*}$ \\
$>70$ years & $0.8 I^{*}(0.47-1.00)^{\mathrm{b}}$ & $0.77^{*}(0.38-1.00)^{\mathrm{b}}$ & $50.6^{*}$ & $44.6^{*}$ \\
\hline
\end{tabular}

Notes: LRx database, January 201 I to September 2014 , Germany. ${ }^{* P}<0.05$ : once-daily vs once-weekly GLP-I RA. ${ }^{\mathrm{a}}$ Total includes male and female patients, as well as patients whose sex was not known. '25th, 75th percentiles.

Abbreviations: GLP-I RA, glucagon-like peptide-I receptor agonist; LRx, longitudinal prescriptions database; PDC, proportion of days covered.
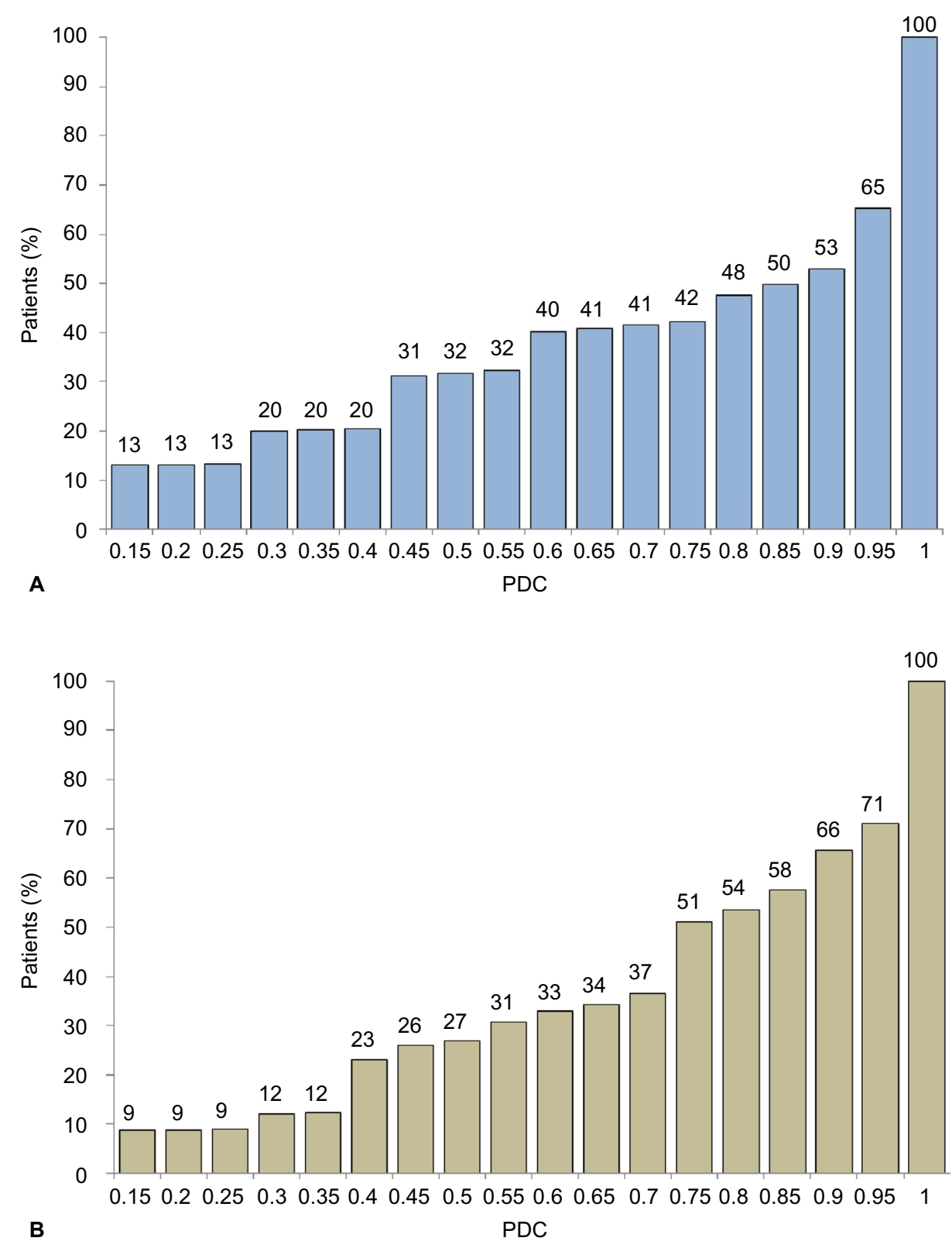

Figure I Cumulative distribution of PDC values.

Note: (A) Exenatide once weekly; (B) Liraglutide once daily.

Abbreviation: PDC, proportion of days covered. 
The odds ratio for having a PDC of $\geq 0.80$ was 1.78 (95\% CI: 1.62-1.96) for exenatide once weekly compared to liraglutide once daily, adjusting for age, sex, and glucose-lowering comedication (Table 3). Comedication with metformin plus other oral drugs or with metformin plus insulin increased the odds of having a PDC $\geq 80$ as compared with cotherapy with metformin alone (Table 3). Interaction between GLP-1RA therapy (once weekly vs once daily) and age groups did not improve the model fitness (Table 3).

\section{Discussion}

This study indicates that therapy adherence to GLP-1 RA was high for 6 months after index date (study period: January 2011-September 2014). Patients with type 2 diabetes treated with exenatide once weekly had significantly better adherence compared with patients on liraglutide once daily.

An important consideration in diabetes care is patient adherence to therapy. ${ }^{4}$ The main consequence of poor adherence to antidiabetic medications is decreased glycemic control, leading to the known complications of diabetes and increased mortality. ${ }^{4}$ Adherence to liraglutide has been shown to be associated with improved glycated hemoglobin outcomes and lower medical costs. ${ }^{7}$ In a study of insulin-treated patients with type 2 diabetes in the UK, medication noncompliance, as assessed by the attending physician or nurse, was an independent risk factor for all-cause mortality (hazard ratio after adjustment for confounding factors: 1.58 ; 95\% CI: $1.17-2.14) .{ }^{8}$ Consistent with findings from this study in Germany, a retrospective cohort study of 6 months' adherence to GLP-1RAs in patients with type 2 diabetes based on a US administrative claim data showed that patients treated with exenatide once weekly had a statistically significantly greater multivariable-adjusted odds of achieving a PDC of $\geq 80 \%$. ${ }^{9}$ The median unadjusted PDC values were 0.78 for exenatide once weekly, 0.50 for exenatide twice daily, and 0.72 for liraglutide once daily. ${ }^{9}$ A study that has evaluated patient satisfaction showed once-weekly formulations of GLP-1 RA exhibited perceived patient convenience, improved quality of life, and fewer perceptions of burdens of treatment relative to traditional diabetes agents. ${ }^{10}$ The lower frequency in administration of the medication may have partly contributed to the good adherence with exenatide once weekly. Another study based on a US claim database revealed twice-daily exenatide (vs once-daily liraglutide), younger age, female sex, living in southern USA, and higher percentage of copayment from the claimant were all associated with poor 12-month adherence. ${ }^{11} \mathrm{~A}$ recent meta-analysis of 12 studies showed that adherence to oral antidiabetic drugs (OADs), measured using medication possession ratio $\geq 80 \%$, was $67.9 \%$ (95\% CI: $59.6 \%-76.3 \%)$ for all OADs, but no direct comparisons between OADs and GLP-1RAs have been made. ${ }^{12}$ In these patient populations, GLP-1RA cotherapy with metformin plus one among the following drugs - sulfonylurea, DPP-4i, or insulin (triple combinations) - was associated with better adherence, whereas dual combinations with DPP-4is, or

Table 3 Odds ratio of having a PDC of at least 0.80 in patients with type 2 diabetes in primary care practices in Germany

\begin{tabular}{|c|c|c|c|c|}
\hline \multirow[t]{2}{*}{ Variable } & \multicolumn{2}{|c|}{ Model without interaction variable } & \multicolumn{2}{|c|}{ Model with interaction variable } \\
\hline & Odds ratio $(95 \% \mathrm{Cl})$ & $P$-value & Odds ratio $(95 \% \mathrm{Cl})$ & $P$-value \\
\hline Exenatide once weekly vs liraglutide once daily & $1.78(1.62-1.96)$ & $<0.0001$ & $1.45(1.18-1.77)$ & 0.0003 \\
\hline \multicolumn{5}{|l|}{ Age, years } \\
\hline $5 \mathrm{I}-60$ vs $\leq 50$ & $1.10(1.03-1.18)$ & 0.0081 & $1.07(0.99-1.16)$ & 0.0738 \\
\hline $6 \mathrm{I}-70$ vs $\leq 50$ & I.II (1.03-I.19) & 0.0058 & $1.04(0.96-1.13)$ & 0.3163 \\
\hline$>70$ vs $\leq 50$ & $0.94(0.87-1.02)$ & 0.1360 & $0.89(0.82-0.98)$ & 0.0134 \\
\hline Exenatide/liraglutide $\times$ age $5 \mathrm{I}-60$ years $^{\mathrm{a}}$ & - & - & $1.13(0.94-1.36)$ & 0.1866 \\
\hline Exenatide/liraglutide $\times$ age $6 \mathrm{I}-70$ years $^{\mathrm{a}}$ & - & - & $1.37(1.14-1.64)$ & 0.0008 \\
\hline Exenatide/liraglutide $\times$ age $>70$ years $^{\mathrm{a}}$ & - & - & $1.30(1.07-1.59)$ & 0.0099 \\
\hline Metformin + sulfonylurea vs metformin & $1.30(1.20-1.42)$ & $<0.0001$ & $1.30(1.20-1.42)$ & $<0.0001$ \\
\hline Metformin + DPP-4i vs metformin & $1.16(1.05-1.28)$ & 0.0042 & $1.16(1.05-1.28)$ & 0.0041 \\
\hline Metformin + insulin vs metformin & $1.48(1.38-1.58)$ & $<0.0001$ & $1.48(1.39-1.58)$ & $<0.0001$ \\
\hline Insulin vs metformin & $0.85(0.76-0.95)$ & 0.0060 & $0.85(0.76-0.96)$ & 0.0066 \\
\hline DPP-4i vs metformin & $0.76(0.65-0.89)$ & 0.0005 & $0.76(0.65-0.89)$ & 0.0005 \\
\hline GLP-IRA monotherapy vs metformin & $0.34(0.30-0.38)$ & $<0.0001$ & $0.34(0.30-0.38)$ & $<0.0001$ \\
\hline Other combinations vs metformin & $0.93(0.84-1.04)$ & 0.1881 & $0.93(0.83-1.03)$ & 0.1732 \\
\hline \multicolumn{5}{|l|}{ Model fitness: } \\
\hline Pseudo- $R^{2}$ & 0.041 & - & 0.041 & - \\
\hline AIC & 36,278 & - & 36,271 & - \\
\hline $\mathrm{BIC}$ & 36,396 & - & 36,413 & - \\
\hline
\end{tabular}

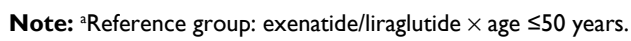

Abbreviations: AIC, Akaike information criterion; BIC, Bayesian information criterion; Cl, confidence interval; DPP-4i, dipeptidyl peptidase 4 inhibitor; GLP-IRA, glucagonlike peptide-I receptor agonist; PDC, proportion of days covered. 
insulin or GLP-1 RA as monotherapy, were related to worse adherence compared with cotherapy with metformin alone. This may reflect the fact that patients who initiated GLP-1RA treatment are usually obese and have poor glycemic control. ${ }^{3}$ Adjustment for cotherapy with other antidiabetic treatments did not change the observed outcome on adherence to GLP1RA treatment. Actually, cotherapy with metformin plus insulin was more common in the liraglutide group than in the exenatide once-weekly group. This may obscure the observed outcome on adherence difference between the two GLP-1RA groups. Unfortunately, information on diabetes duration, diabetes-related complications, glycated hemoglobin levels, and other clinical characteristics were not available in the database. The impact of these factors on therapy adherence cannot be evaluated. This is one of the limitations of the study. Another limitation of the study is that patients are not randomly assigned to receive treatments, which is a common limitation for observational studies.

\section{Conclusion}

This study shows better therapy adherence with once-weekly regimens compared with once-daily GLP-1 RA treatment. Further studies are required to determine the clinical and patient-related factors associated with good treatment compliance, as well as the impact of compliance on glycemic control and long-term health outcomes.

\section{Disclosure}

QQ, MJNMO, SG, and KJ are employees of AstraZeneca. KK is an employee of IMS Health, with no conflicts of interest. The authors have no other conflicts of interest in this work.

\section{References}

1. Holst JJ, Vilsboll T. Combining GLP-1 receptor agonists with insulin: therapeutic rationales and clinical findings. Diabetes Obes Metab. 2013;15(1):3-14.

2. Werner U. Effects of the GLP-1 receptor agonist lixisenatide on postprandial glucose and gastric emptying: preclinical evidence. J Diabetes Complications. 2014;28(1):110-114.

3. Garber AJ. Long-acting glucagon-like peptide 1 receptor agonists. A review of their efficacy and tolerability. Diabetes Care. 2011;34(suppl 2):S279-S284

4. García-Pérez LE, Alvarez M, Dilla T, Gil-Guillén V, Orozco-Beltrán D. Adherence to therapies in patients with type 2 diabetes. Diabetes Ther. 2013;4(2):175-194.

5. Richter H, Dombrowski S, Hamer H, Hadji P, Kostev K. Use of a German longitudinal prescription database (LRx) in pharmacoepidemiology. Ger Med Sci. 2015; 13:Doc14.

6. Swart E, Gothe H, Geyer S, et al; German Society for Social Medicine and Prevention; German Society for Epidemiology. Gute Praxis Sekundärdatenanalyse (GPS): Leitlinien und Empfehlungen. [Good practice of secondary data analysis (GPS): guidelines and recommendations]. Gesundheitswesen. 2015;77(2):120-126. German.

7. Buysman EK, Liu F, Hammer M, Langer J. Impact of medication adherence and persistence on clinical and economic outcomes in patients with type 2 diabetes treated with liraglutide: a retrospective cohort study. Adv Ther. 2015;32(4):341-355.

8. Currie CJ, Peyrot M, Morgan CL, et al. The impact of treatment noncompliance on mortality in people with type 2 diabetes. Diabetes Care. 2012;35(6):1279-1284.

9. Johnston SS, Nguyen H, Felber E, et al. Retrospective study of adherence to glucagon-like peptide-1 receptor agonist therapy in patients with type 2 diabetes mellitus in the United States. Adv Ther. 2014;31(11):1119-1133.

10. Polonsky WH, Fisher L, Hessler D, Bruhn D, Best JH. Patient perspectives on once-weekly medications for diabetes. Diabetes Obes Metab. 2011;13(2):144-149.

11. Malmenäs M, Bouchard JR, Langer J. Retrospective real-world adherence in patients with type 2 diabetes initiating once-daily liraglutide $1.8 \mathrm{mg}$ or twice-daily exenatide $10 \mu \mathrm{g}$. Clin Ther. 2013;35(6):795-807.

12. Iglay K, Cartier SE, Rosen VM, et al. Meta-analysis of studies examining medication adherence, persistence, and discontinuation of oral antihyperglycemic agents in type 2 diabetes. Curr Med Res Opin 2015;31(7):1283-1296.
Diabetes, Metabolic Syndrome and Obesity: Targets and Therapy is an international, peer-reviewed open-access journal committed to the rapid publication of the latest laboratory and clinical findings in the fields of diabetes, metabolic syndrome and obesity research Original research, review, case reports, hypothesis formation, expert opinion and commentaries are all considered for publication. The manuscript management system is completely online and includes a very quick and fair peer-review system, which is all easy to use. Visit http://www.dovepress.com/testimonials.php to read real quotes from published authors. 